Psychological Topics, 27 (2018), 1, 17-32

Original Scientific Paper - UDC - 591.434

\title{
Gut Microbiota and its Role in Human Health
}

\author{
Mirjana Rajilić-Stojanović \\ University of Belgrade, Faculty of Technology and Metallurgy, \\ Department for Biochemical Engineering and Biotehnology, Serbia
}

\begin{abstract}
Humans live in a close association with a complex microbial ecosystem that is collectively termed microbiota. Microbiota is concentrated in the last part of the gastrointestinal tract, where it ferments undigested food residues and produces various metabolites that have a systemic influence on human physiology. The composition of microbiota is influenced by genetic and environmental factors that shape a unique ecosystem in each human. Despite considerable compositional variations, the functional output of the ecosystem is highly similar in all healthy individuals. Although it is still not possible to define normal microbiota, comparisons between patients suffering from a number of chronic diseases with unknown etiology and controls have shown that patients have specific, dysbiotic microbiota composition. While it still remains to be determined if the microbiota dysbiosis is an etiological factor or a consequence of a disease, these findings have initiated intensive microbiota research. Numerous proven functions of microbiota include contribution to the digestion, synthesis of essential metabolites (vitamins and amino acids) and the intensive crosstalk with the immune, the endocrine and the nervous system. Even though this field of research is still in an early stage, it is clear that microbial metabolites can have various effects on humans including direct beneficial effect, toxicity, but also more subtle interactions since microbial products can act as immune regulating or neuro-signaling molecules. The complex network of bidirectional interactions between microbiota and humans is unexplored but highly potent for development of novel strategies to preserve and improve health.
\end{abstract}

Keywords: microbiota, composition, dysbiosis, human health

\section{Introduction}

Humans live in a close relationship with microorganisms that are collectively termed microbiota. Two other terms are also widely used to refer to the same ecosystem. Microflora is a synonym that is currently abandoned since biota indicates presence of living beings, while flora is used as collective term for plants.

Mirjana Rajilić-Stojanović, Department for Biochemical Engineering and Biotehnology, Faculty of Technology and Metallurgy, Karnegijeva 4, 11000 Belgrade, Serbia. E-mail: mrajilic@tmf.bg.ac.rs 
Microbiome was originally introduced as a term to refer to collective microbial genomes, although today it is used as a term to collectively address microorganisms, their genomes and the surrounding environmental conditions (Marchesi \& Ravel, 2015). The majority of human-associated microorganisms are inhabiting the digestive tract, in particular the colon, although nasal passage, oral cavity, skin and urogenital tract are also densely populated (The Human Microbiome Project, 2012). Traditionally, human associated microorganisms were considered as commensals, indicating the absence of any harmful but also beneficial activity towards the host. However, current research proved a whole range of beneficial effects of human microbiota suggesting that associated microoganisms are symbiotic species essential for our wellbeing. The recognition of the microbiota's importance is probably the best illustrated through a suggestion that it should be considered as a "forgotten organ" (O'Hara \& Shanahan, 2006).

The symbiotic relationship between higher animals and associated microorganisms has been recognized for a long time for herbivores, in particular ruminants, as extraction of energy from ingested food in these animals is highly dependent on enzymatic activity of their intestinal microbes (Jami, Israel, Kotser, \& Mizrahi, 2013). Humans similar to other omnivores do not depend in such a large extent on the energy extracted by fermentation. It is clear that human intestinal microbiota also contributes to energy extraction from indigested food (Cummings \& Macfarlane, 1997), the colon should be considered as a sophisticated bioreactor (Swidsinski et al., 2016), which activity has much more complex impact on human health. Numerous functions of gut microbiota include synthesis of essential amino acids and vitamins, contribution to steroid molecules circulation (including bile acids and sex hormones), education of the immune system and production of various bioactive compounds with systemic impact on health (Rajilić-Stojanović, 2013).

The microbiota is very complex as it is composed of representatives of all three domains of life - Bacteria, Archaea and Eukarya accompanied by viruses (RajilićStojanović \& de Vos, 2014). However, bacteria are by far the most predominant and in most studies the only studied component of the ecosystem. There are thousands of possible microbial inhabitants, although each of human is populated by approximately 500 species that represent a unique and stable ecosystem. There is quite some controversy regarding the stability of the microbiota. On one hand it has been shown that various life style changes including dietary shift of quitting smoking can cause changes in the gut microbiota (Biedermann et al., 2014; Wu et al., 2011). On the other hand, one of the first applications of molecular profiling techniques have indicated stable and individual-specific microbiota signature (Zoetendal, Akkermans, \& de Vos, 1998). The reason for, on the first sight, contradictory reports is primarily methodological. The majority of microbiota studies employ sequencing and quantitative interpretation of the obtained number of reads per taxonomic group. This approach is not sensitive enough to identify microbiota profiles irrespective of quantitative contribution of particular taxa in the ecosystem. However, ultra-deep 
sequencing and DNA microarrays application on samples collected over periods longer than a decade have clearly shown that each person harbors microbiota composed of particular species that define an individual specific microbiota signature, while quantitative contribution of microbiota constituents changes in response to environmental triggers (Faith et al., 2013; Rajilić-Stojanović, Heilig, Tims, Zoetendal, \& de Vos, 2012).

\section{Methods to Study Microbiota}

The history of microbiota research is very long, since the first intestinal bacterium was isolated from healthy children already in 1886. This first isolate was at that time known as Bacillus coli commune, but was renamed to honor its discoverer - dr Theodor Escherich to Escherichia coli (Shulman, Friedmann, \& Sims, 2007). For many years intestinal microbiota was studied using classical microbiological methods, but the recovery of its members was poor, since the majority of intestinal microbes are strict anaerobes. The development of methods for anaerobic growth in 1960s (Hungate, 1969), enabled more adequate research of the intestinal microbiota and many relevant intestinal species were described in the 1970s (Finegold et al., 1977; Holdeman \& Moore, 1974). Although it was possible to capture as many as $88 \%$ of intestinal counts, anaerobic cultivation was not widely applied due to numerous technical challenges. Namely, for profiling of a single sample it was necessary to apply dozens of different cultivation media, at different dilutions since intestinal microbes can be present in very different densities (e.g. in feces Bacteroides spp. are present up to 1011cells/g (Eggerth \& Gagnon, 1933), while Actinomyces spp. are present in density of 102-103 cells/g (Hoyles et al., 2012). Furthermore, due to the enormous and still unexplored diversity it was impossible to assign all obtained isolates to species level identity (Moore \& Holdeman, 1974).

The true revolution of this field of research occurred with the introduction of molecular methods that allowed analysis not only of community structure but also of functions of complex ecosystems (Figure 1). In particular, the application of sequence analysis of the phylogenetic marker - small subunit ribosomal RNA sequence (SSU rRNA) - enabled analysis of the microbial diversity without the need for cultivation but also the development of various profiling and quantification methods that have shown the importance of the microbiota (Namsolleck et al., 2004). SSU rRNA is also referred as 16S rRNA in prokaryotes and 18S rRNA in eukaryotes, due to its different size in different life forms. It is a building part of ribosomes and its sequence, which is composed of conserved and nine variable regions, has not change much through evolution. The level of similarity of the SSU rRNA sequences are indicative of the relatedness between species, and the first application of this phylogenetic marker facilitated the discovery of the third domain of life - Archaea (Woese, Kandler, \& Wheelis, 1990). Applied on intestinal isolates, analysis of the SSU rRNA sequence indicated the need for reclassification of many of the 
misclassified species, which is the best illustrated through an example of the Clostridium genus (Collins et al., 1994). It was shown that only a small fraction of species classified to this genus are highly related and are members of Clostridium genus sensu stricto, while others represent members of different genera in distantly related families. This led to the reclassification of many species, including C. difficile as Clostridioides difficile (Lawson, Citron, Tyrrell, \& Finegold, 2016) but also to the introduction of so called Clostridium clusters, of which clusters IV and XIVa are highly abundant in gut microbiota (Rajilić-Stojanović et al., 2009).

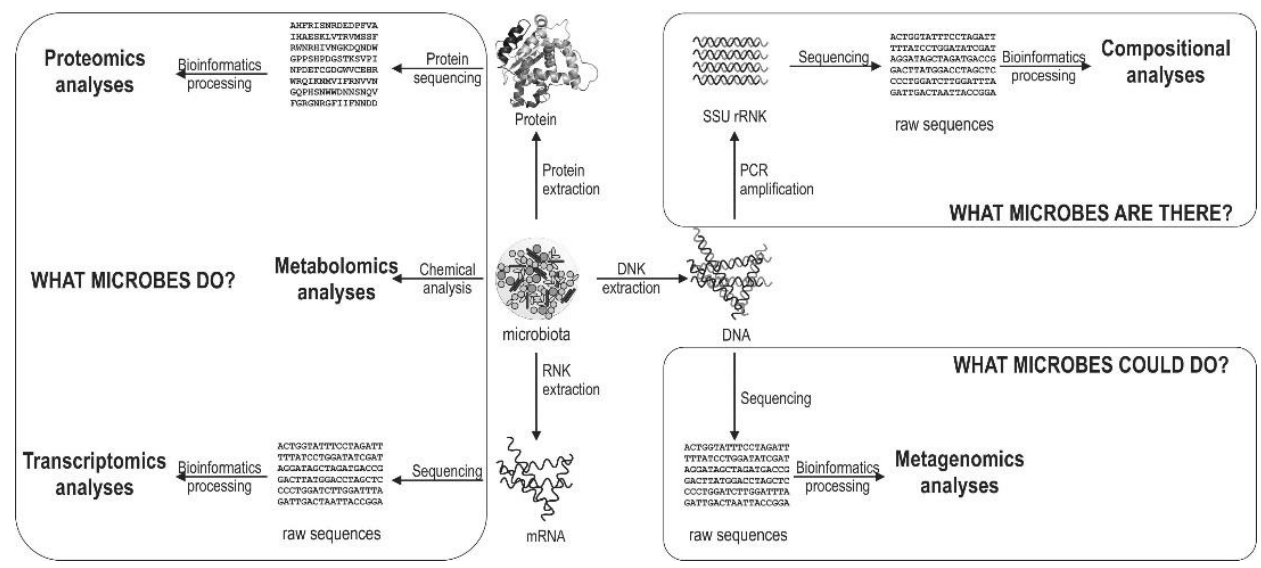

Figure 1. Schematic representation of molecular methods available for studying microbiota, composition and function.

Analysis of the SSU rRNA encoding gene sequence starting from the total genomic DNA isolated from an intestinal sample showed that many (about $~ 80 \%$ ) of the intestinal inhabitants are still uncultured species (Rajilić-Stojanović, Smidt, \& de Vos, 2007). This indicates that we still know very little about the identity and function of our microbial companions. Nevertheless, even without knowing the true identity and function of microbiota, compassion between different populations showed specific microbiota signatures for different age groups or geographic origin (Yatsunenko et al., 2012). Even more relevant are indications of presence of specific microbiota structure in relation to different diseases including obesity, diabetes, irritable bowel syndrome, colon cancer and autism (Castellarin et al., 2012; Larsen et al., 2010; Ley, Turnbaugh, Klein, \& Gordon, 2006; Rajilić-Stojanović et al., 2011; Williams, Hornig, Parekh, \& Lipkin, 2012). This disturbed ecosystem composition is often termed dysbiosis in contrast to eubyosis. Both terms are indicating presence of a stable ecological state of the microbiota, of which ecosystem in dysbiosis has lost a beneficial interaction with the host (Costello, Stagaman, Dethlefsen, Bohannan, \& Relman, 2012). It is still not clear if dysbiosis precedes the development of the disease and therefore is its etiological factor or it is its 
consequence. However, the experiments with germ free animals indicate that microbiota could be an etiological factor since phenotype of several diseases has been transferred from patients to experimental animals upon fecal microbiota transplantation (Collins, Kassam, \& Bercik, 2013; Ridaura et al., 2013).

Although it is of undoubted interest to study the community structure, it is even more relevant to assess the function of the microbiota, to understand its role in human health. Here it is important to note that it has been shown that despite differences in composition, microbiota performs similar (the same) functions. This phenomenon that phylogenetically distant species can perform the same function is known as a functional redundancy (The Human Microbiome Project, 2012). Function of the microbiota can be assessed by analysis of the produced metabolites (metabolomics), total proteins (proteomics) or all transcribed messenger RNAs (transcriptomics, Figure 1). The analysis of proteomics and transcriptomics data are linked with numerous technical challenges primarily due to the still unexplored identity of the majority of proteins and very short life of prokaryotic mRNAs. Therefore, transcriptomics studies often instead of mRNA report results of the rRNA analysis, which provide insight into active members of the community (Bashiardes, Zilberman-Schapira, \& Elinav, 2016). Metagenomics is the technique that allows researchers to assess the total genomic material, and provide a view of the genetic potential of the entire community. Since there is considerable genomic sequence variation between strains of the same species (as exemplified on Lactobacillus plantarum species (Molenaar et al., 2005) and since for more than half of the cultured intestinal species not even a single genome has been sequenced and annotated (Rajilić-Stojanović \& de Vos, 2014) it is clear that databases for matagenomics data interpretation are still immature. Nevertheless, this method combined with ultra-deep sequencing can be powerful in revealing both compositional and functional shifts associated with various treatments, as shown when studying the effect of metformin on microbiota and metabolic parameters of type 2 diabetes patients (Wu et al., 2017).

\section{Factors Shaping Microbiota}

Microbiota of each human represents a unique ecosystem that is composed under influence of many factors (Figure 2). For a long time it has been believed that babies are sterile in the womb and that are inoculated by surrounding microorganisms during the delivery. Novel research shows that microbes are present in the amniotic fluid, the placenta, the umbilical cord and in the first stool - meconium (Collado, Rautava, Aakko, Isolauri, \& Salminen, 2016). However there is an important influence of the environment and the microbiota that develops in infants born via Cesarean $(\mathrm{C}$-)section is notably different than that in vaginally born infants and more skin and hospital related microorganisms are found in these babies (Bäckhed et al., 2015). Since C-section is linked to various health risks including auto-immune diseases such as asthma and allergies (Sevelsted, Stokholm, Bønnelykke, \& 
Bisgaard, 2015), it is believed that these risks are linked to the specific microbiota signatures found in these babies and strategies were developed to inoculate newborns with mother's vaginal microorganisms (Dominguez-Bello et al., 2016). In addition to the mode of delivery another important factor that strongly influences microbiota development is infant feeding as it has been shown that breast-fed infants have less diverse and Bifidobacterium spp. predominated microbiota (Bäckhed et al., 2015). Mother's milk contains probiotic microbes, numerous prebiotic acting oligosaccharides and antimicrobial peptides (Cabrera-Rubio et al., 2012; Kunz, Rudloff, Baier, Klein, \& Strobel, 2000), which indicates that this natural food for infants is designed to stimulate development of specific microbial community in the infants' intestine. This is probably the most illustrative example that shows the natural regulation of microbiota, which is indicative of its importance for human wellbeing.

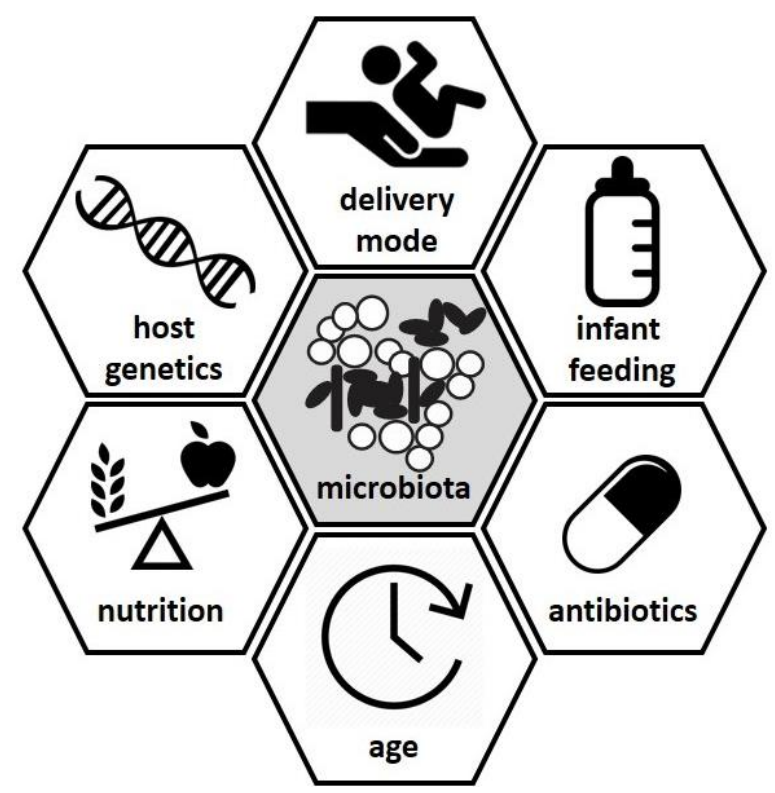

Figure 2. Schematic representation of factors that influence intestinal microbiota composition.

Another important factor that introduces prominent changes in the microbiota is the introduction of solid foods. Introduction of solid foods causes microbiota diversification (Bäckhed et al., 2015), and it has been shown that too early diversification and adult like microbiota in young children might contribute to development of the atopic diseases (Nylund et al., 2012). At age of one already most of the intestinal microbes are acquired and until the introduction of the molecular techniques it was believed that at that age microbiota is already adult-like (Mitsuoka, 1992). Currently it is widely accepted that microbiota at age of three is adult like 
(Yatsunenko et al., 2012), although quantitative differences have been observed even when comparing adults and children of 7-12 years of age (Hollister et al., 2015), or even adolescents (Agans et al., 2011). Despite the observed differences at later age, it is clear that the widest window of opportunity to shape microbiota and influence health is at very early age.

In addition to mode of the delivery and infant feeding other factors such as presence of siblings or pets, antibiotic treatment and hospitalization also influence microbiota development (Laursen et al., 2015; Tun et al., 2017). Among these antibiotics have the most profound impact, although this depends on the antibiotic type (Ianiro, Tilg, \& Gasbarrini, 2016). An interesting study conducted in Finland showed that macrolide antibiotic in contrast penicillin, both were prescribed for respiratory infections, induces dramatic changes in microbiota that are associated with increased obesity and allergy development risk (Korpela et al., 2016). Another important cofounder in microbiota shaping is diet. Dramatic differences in microbiota composition have been shown when European children were compared with rural African children (De Filippo et al., 2010). The analyses have shown that African children have an enriched population of bacteria that are capable of complex carbohydrate degradation, and although it has been suggested that diet is the major driver of the observed differences in the microbiota composition, it is clear that there are numerous genetic, cultural, hygienic and other lifestyle differences between the two compared populations that could have had their contribution to the observed dissimilarity. Since, other similar comparisons have shown a notable loss of microbial diversity and a composition shift in the developed societies, it has been suggested that microbiota change is underlining the increasing incidence of chronic diseases in the developed world. The data supporting this hypothesis was generated in a recent study that showed specific microbiota patterns and metabolites associated with increased risk for colon cancer development in African American population when compared to Native Africans (Ou et al., 2013). A dietary swop between these two populations induced shifts in microbiota composition and function, but also in the colonic biopsy histology indicating that diet is indeed the major driver in microbiota mediated health risks (O'Keefe et al., 2015). Even among elderly population, healthy and diverse diet was shown to be an important factor for reducing frailty and markers of inflammation while keeping microbiota diverse (Claesson et al., 2011).

As expected, genetics is also an important factor that influences microbiota composition. Monozygotic twins have more alike microbiota than dizygotic twins and the level of similarity decreases with decreasing relatedness (Tims et al., 2013; Zoetendal, Akkermans, Akkermans-van Vliet, de Visser, \& de Vos, 2001). Here, again, it is impossible to exclude other factors, such as shared environment, and similar dietary habits that are confounding factors in shaping microbiota. The undoubtable influence of the genetics on the microbiota is confirmed through established connection between specific genetic variants and microbiota composition 
as shown for several genes (Blekhman et al., 2015; Olivares et al., 2015; Wacklin et al., 2014). The influence of host exceeds that of genetic background since specific micro RNAs produced by gut epithelium cells are able to enter bacterial cells and regulate their function (Liu et al., 2016). Experiments with laboratory animals showed that inability to produce these micro RNAs was linked with microbiota compositional shift and more severe parameters of the induced colitis. This sophisticated regulation is complemented with the immune regulation both by innate and adaptive elements of the immune system and indicates the complexity of the bidirectional host-microbe interactions.

\section{Link between Microbiota and Behavior}

There is an increasing evidence showing the importance of microbiota for systemic health, and one of the most intriguing aspects of microbiota influence is its contribution to the so-called gut brain axis. There are several health conditions that linked with behavioral changes and specific microbiota signatures. These include irritable bowel syndrome (IBS) (Jeffery et al., 2012; Rajilić-Stojanović et al., 2011), obesity (Ley et al., 2006) and even autism (Strati et al., 2017; Williams et al., 2012).

The role of microbiota in obesity is complex and bidirectional. On one hand the disturbed microbiota could be a consequence of specific dietary habits of obese individuals, while on the other hand it could contribute to excessive energy extraction from diet (Turnbaugh et al., 2006). In addition, it has been shown that microbial metabolites, such as propionate, can act as satiety sensation molecules and therefore contribute to the eating behavior (Chambers et al., 2014), while propionate together with other short chain fatty acids produced during fermentation of dietary fiber promote metabolic benefits via gut-brain neural circuits (De Vadder et al., 2014). This basically means that introduction of non-digestible carbohydrates in the diet can promote activity of carbohydrate fermenting bacteria in the colon. As a consequence, beneficial metabolites that take part in blood glucose level regulation and satiety sensation will be produced, and this will contribute to healthy eating behavior.

It is well established that in addition to gastrointestinal symptoms a large proportion (70-90\%) of IBS patients have psychiatric comorbidity such as anxiety or depression (Garakani et al., 2003). Even though IBS is considered to be a functional disorder, recent years of research have shown that objective, measurable traits of this condition exist and include specific microbiota composition in at least some of the patients (Jeffery et al., 2012; Rajilić-Stojanović et al., 2011). Microbiota contribution to both gastrointestinal and psychiatric symptoms of IBS patients could be mediated through its impact on serotonin synthesis. The initial interest for studying this link came from the observation that germ free animals have about 6 fold lower level of serum serotonin level than conventional animals (Wikoff et al., 2009). Further research confirmed that serotonin is produced by hosts' enterochromaffin cells upon stimulation of these cells by microbial metabolites (Yano et al., 2015). While specific 
microbes needed for this stimulation have not been identified yet, it seems that one of the major carbohydrate fermentation metabolites - butyrate is essential for serotonin synthesis induction (Reigstad et al., 2015).

Autism represents one of the most intriguing conditions linked with microbiota dysbiosis. Specific traits in microbiota signatures, although rarely reproduced, have been repeatedly reported (De Angelis et al., 2013; Strati et al., 2017; Williams et al., 2012). However, the most convincing study indicating the importance of microbiota in autism comes from an open-label study that reported successful fecal microbiota transplantation in autistic children (Kang et al., 2017). Change of the microbiota community caused improvement of gastrointestinal but also behavioral symptoms in the treated children.

In addition to fecal microbiota transplantation, which causes dramatic changes of the intestinal ecosystem, literature data indicates that less aggressive microbiotatargeting therapies can have a significant effect on behavior. The effect of early age probiotic treatment of Finish infants was evaluated 13 years later, and showed that placebo in contrast to probiotic treated children had significantly higher incidence of diagnosed attention deficit hyperactivity disorder and Asperger syndrome (Pärtty, Kalliomäki, Wacklin, Salminen, \& Isolauri, 2015). The observed neuropsychiatric disorders were linked with lower abundance of Bifidobacterium spp. in 13 year old children. Another study showed that treatment with a probiotic can influence serum kyneurenic acid to kynurenine ratio (neuroprotective ratio) in line with attenuation of pro-inflammatory immune responses in experimental animals (Desbonnet, Garrett, Clarke, Bienenstock, \& Dinan, 2008). Finally, it is of importance to note that recently the probiotic strains with antidepressant properties have been successfully applied on humans (Wallace \& Milev, 2017).

\section{Conclusions}

Microbiota is an extremely numerous and complex ecosystem that has a profound and systemic impact on human health. Its complexity, variation, functional redundance and bidirectional communication with the host hamper establishment of clear cause-relation links with a number of diseases in which microbiota dysbiosis has been detected. A number of genetic and environmental factors shape microbiota and the most relevant imprint in this ecosystem and subsequent health is made in very early childhood. Manipulation of microbiota at older age can be performed by dietary shifts, probiotic treatments or fecal microbiota transplantation. These therapies can lied to the improvement in various health aspects, proving that microbiota targeted strategies are promising tools for preserving and improving health. 


\section{References}

Agans, R., Rigsbee, L., Kenche, H., Michail, S., Khamis, H. J., \& Paliy, O. (2011). Distal gut microbiota of adolescent children is different from that of adults. FEMS Microbiology Ecology, 77(2), 404-412.

Bäckhed, F., Roswall, J., Peng, Y., Feng, Q., Jia, H., Kovatcheva-Datchary, P., ... Wang, J. (2015). Dynamics and stabilization of the human gut microbiome during the first year of life. Cell Host \& Microbe, 17(5), 690-703.

Bashiardes, S., Zilberman-Schapira, G., \& Elinav, E. (2016). Use of metatranscriptomics in microbiome research. Bioinformatics and Biology Insights, 10, 19-25.

Biedermann, L., Brülisauer, K., Zeitz, J., Frei, P., Scharl, M., Vavricka, S. R., ... Schuppler, M. (2014). Smoking cessation alters intestinal microbiota: Insights from quantitative investigations on human fecal samples using FISH. Inflammatory Bowel Diseases, 20(9), 1496-1501.

Blekhman, R., Goodrich, J. K., Huang, K., Sun, Q., Bukowski, R., Bell, J. T., ... Clark, A. G. (2015). Host genetic variation impacts microbiome composition across human body sites. Genome Biology, 16(1), 191.

Cabrera-Rubio, R., Collado, M. C., Laitinen, K., Salminen, S., Isolauri, E., \& Mira, A. (2012). The human milk microbiome changes over lactation and is shaped by maternal weight and mode of delivery. The American Journal of Clinical Nutrition, 96(3), 544-551.

Castellarin, M., Warren, R. L., Freeman, J. D., Dreolini, L., Krzywinski, M., Strauss, J., ... Holt, R. A. (2012). Fusobacterium nucleatum infection is prevalent in human colorectal carcinoma. Genome Research, 22(2), 299-306.

Chambers, E. S., Viardot, A., Psichas, A., Morrison, D. J., Murphy, K. G., Zac-Varghese, S. E. K., ... Frost, G. (2014). Effects of targeted delivery of propionate to the human colon on appetite regulation, body weight maintenance and adiposity in overweight adults. Gut, 64, 1744-1754.

Claesson, M. J., Cusack, S. N., O'Sullivan, O., Greene-Diniz, R., de Weerd, H., Flannery, E., ... O'Toole, P. W. (2011). Composition, variability, and temporal stability of the intestinal microbiota of the elderly. Proceedings of the National Academy of Sciences of the United States of America, 108 (Suppl. 1), 4586-4591.

Collado, M. C., Rautava, S., Aakko, J., Isolauri, E., \& Salminen, S. (2016). Human gut colonisation may be initiated in utero by distinct microbial communities in the placenta and amniotic fluid. Scientific Reports, 6, 23129.

Collins, M., Lawson, P., Willems, A., Cordoba, J., Fernandez-Garayzabal, J., Garcia, P., ... Farrow, J. (1994). The phylogeny of the genus Clostridium: Proposal of five new genera and eleven new species combinations. International Journal of Systematic Bacteriology, 44(4), 812-826.

Collins, S. M., Kassam, Z., \& Bercik, P. (2013). The adoptive transfer of behavioral phenotype via the intestinal microbiota: Experimental evidence and clinical implications. Current Opinion in Microbiology, 16(3), 240-245. 
Costello, E. K., Stagaman, K., Dethlefsen, L., Bohannan, B. J. M., \& Relman, D. A. (2012). The Application of ecological theory toward an understanding of the human microbiome. Science, 336(6086), 1255-1262.

Cummings, J. H., \& Macfarlane, G. T. (1997). Role of intestinal bacteria in nutrient metabolism. Clinical Nutrition, 16(1), 3-11.

De Angelis, M., Piccolo, M., Vannini, L., Siragusa, S., De Giacomo, A., Serrazzanetti, D. I., ... Francavilla, R. (2013). Fecal microbiota and metabolome of children with autism and pervasive developmental disorder not otherwise specified. PLOS ONE, 8(10), e76993.

De Filippo, C., Cavalieri, D., Di Paola, M., Ramazzotti, M., Poullet, J. B., Massart, S., ... Lionetti, P. (2010). Impact of diet in shaping gut microbiota revealed by a comparative study in children from Europe and rural Africa. Proceedings of the National Academy of Sciences of the United States of America, 107(33), 14691-14696.

De Vadder, F., Kovatcheva-Datchary, P., Goncalves, D., Vinera, J., Zitoun, C., Duchampt, A., ... Mithieux, G. (2014). Microbiota-generated metabolites promote metabolic benefits via gut-brain neural circuits. Cell, 156(1), 84-96.

Desbonnet, L., Garrett, L., Clarke, G., Bienenstock, J., \& Dinan, T. G. (2008). The probiotic Bifidobacteria infantis: An assessment of potential antidepressant properties in the rat. Journal of Psychiatric Research, 43(2), 164-174.

Dominguez-Bello, M. G., De Jesus-Laboy, K. M., Shen, N., Cox, L. M., Amir, A., Gonzalez, A., ... Clemente, J. C. (2016). Partial restoration of the microbiota of cesarean-born infants via vaginal microbial transfer. Nature Medicine, 22(3), 250-253.

Eggerth, A. H., \& Gagnon, B. H. (1933). The bacteroides of human feces. Journal of Bacteriology, 25, 389-413.

Faith, J. J., Guruge, J. L., Charbonneau, M., Subramanian, S., Seedorf, H., Goodman, A. L., ... Gordon, J. I. (2013). The long-term stability of the human gut microbiota. Science, $341(6141)$.

Finegold, S. M., Vera, L. S., Paul, T. S., Harvey, A. E., Shirley, M. L., \& Ronald, L. P. (1977). Fecal microbial flora in seventh day Adventist populations and control subjects. The American Journal of Clinical Nutrition, 30, 1781-1792.

Garakani, A., Win, T., Virk, S., Gupta, S., Kaplan, D., \& Masand, P. S. (2003). Comorbidity of irritable bowel syndrome in psychiatric patients: A review. The American Journal of Therapeutics, 10(1), 61-67.

Holdeman, L. V., \& Moore, W. E. C. (1974). New genus, Coprococcus, twelve new species, and emended description of four previously described species of bacteria from human feces. International Journal of Systematic Bacteriology, 24(2), 260-277.

Hollister, E. B., Riehle, K., Luna, R. A., Weidler, E. M., Rubio-Gonzales, M., Mistretta, T.A., ... Versalovic, J. (2015). Structure and function of the healthy pre-adolescent pediatric gut microbiome. Microbiome, 3(1), 36. 
Hoyles, L., Honda, H., Logan, N. A., Halket, G., La Ragione, R. M., \& McCartney, A. L. (2012). Recognition of greater diversity of Bacillus species and related bacteria in human faeces. Research in Microbiology, 163(1), 3-13.

Hungate, R. E. (1969). Methods in microbiology (Vol. 3B). London: Academic Press.

Ianiro, G., Tilg, H., \& Gasbarrini, A. (2016). Antibiotics as deep modulators of gut microbiota: Between good and evil. Gut, 65(11), 1906.

Jami, E., Israel, A., Kotser, A., \& Mizrahi, I. (2013). Exploring the bovine rumen bacterial community from birth to adulthood. The ISME Journal, 7(6), 1069-1079.

Jeffery, I. B., Toole, P. W., Öhman, L., Claesson, M. J., Deane, J., Quigley, E. M. M., \& Simrén, M. (2012). An irritable bowel syndrome subtype defined by species-specific alterations in faecal microbiota. Gut, 61(7), 997.

Kang, D.-W., Adams, J. B., Gregory, A. C., Borody, T., Chittick, L., Fasano, A., ... Krajmalnik-Brown, R. (2017). Microbiota transfer therapy alters gut ecosystem and improves gastrointestinal and autism symptoms: An open-label study. Microbiome, $5(1), 10$.

Korpela, K., Salonen, A., Virta, L. J., Kekkonen, R. A., Forslund, K., Bork, P., \& de Vos, W. M. (2016). Intestinal microbiome is related to lifetime antibiotic use in Finnish preschool children. Nature Communications, 7, 10410.

Kunz, C., Rudloff, S., Baier, W., Klein, N., \& Strobel, S. (2000). Oligosaccharides in human milk: Structural, functional, and metabolic aspects. Annual Review of Nutrition, 20(1), 699-722.

Larsen, N., Vogensen, F. K., van den Berg, F. W. J., Nielsen, D. S., Andreasen, A. S., Pedersen, B. K., ... Jakobsen, M. (2010). Gut microbiota in human adults with type 2 diabetes differs from non-diabetic adults. PLOS ONE, 5(2), e9085.

Laursen, M. F., Zachariassen, G., Bahl, M. I., Bergström, A., Høst, A., Michaelsen, K. F., \& Licht, T. R. (2015). Having older siblings is associated with gut microbiota development during early childhood. BMC Microbiology, 15(1), 154.

Lawson, P. A., Citron, D. M., Tyrrell, K. L., \& Finegold, S. M. (2016). Reclassification of Clostridium difficile as Clostridioides difficile (Hall and O'Toole 1935) Prévot 1938. Anaerobe, 40 (Supplement C), 95-99.

Ley, R. E., Turnbaugh, P. J., Klein, S., \& Gordon, J. I. (2006). Microbial ecology: Human gut microbes associated with obesity. Nature, 444, 1022-1023.

Liu, S., da Cunha, A. P., Rezende, R. M., Cialic, R., Wei, Z., Bry, L., ... Weiner, H. L. (2016). The host shapes the gut microbiota via fecal microRNA. Cell Host \& Microbe, 19(1), 32-43.

Marchesi, J. R., \& Ravel, J. (2015). The vocabulary of microbiome research: A proposal. Microbiome, 3(1), 31.

Mitsuoka, T. (1992). Intestinal flora and aging. Nutrition Reviews, 50(12), 438-446. 
Molenaar, D., Bringel, F., Schuren, F. H., de Vos, W. M., Siezen, R. J., \& Kleerebezem, M. (2005). Exploring Lactobacillus plantarum genome diversity by using microarrays. Journal of Bacteriology, 187(17), 6119-6127.

Moore, W. E. C., \& Holdeman, L. V. (1974). Special problems associated with the isolation and identification of intestinal bacteria in fecal flora studies. The American Journal of Clinical Nutrition, 27, 1450-1455.

Namsolleck, P., Thiel, R., Lawson, P., Holmstrøm, K., Rajilic, M., Vaughan, E. E., ... Blaut, M. (2004). Molecular methods for the analysis of gut microbiota. Microbial Ecology in Health and Disease, 16, 71-85.

Nylund, L., Satokari, R., Nikkilä, J., Rajilić-Stojanović, M., Kalliomäki, M., Isolauri, E., ... de Vos, W. M. (2012). Microarray analysis reveals marked intestinal microbiota aberrancy in infants having eczema compared to healthy children in at-risk for atopic disease. BMC Microbiology, 13, 12.

O'Hara, A. M., \& Shanahan, F. (2006). The gut flora as a forgotten organ. EMBO Reports, 7(7), 688-693.

O'Keefe, S. J. D., Li, J. V., Lahti, L., Ou, J., Carbonero, F., Mohammed, K., ... Zoetendal, E. G. (2015). Fat, fibre and cancer risk in African Americans and rural Africans. Nature Communications, 6, 6342 .

Olivares, M., Neef, A., Castillejo, G., Palma, G. D., Varea, V., Capilla, A., ... Sanz, Y. (2015). The HLA-DQ2 genotype selects for early intestinal microbiota composition in infants at high risk of developing coeliac disease. Gut, 64(3), 406.

Ou, J., Carbonero, F., Zoetendal, E. G., DeLany, J. P., Wang, M., Newton, K., ... O'Keefe, S. J. D. (2013). Diet, microbiota, and microbial metabolites in colon cancer risk in rural Africans and African Americans. The American Journal of Clinical Nutrition, 98(1), 111-120.

Pärtty, A., Kalliomäki, M., Wacklin, P., Salminen, S., \& Isolauri, E. (2015). A possible link between early probiotic intervention and the risk of neuropsychiatric disorders later in childhood: A randomized trial. Pediatric Research, 77, 823.

Rajilić-Stojanović, M. (2013). Function of the microbiota. Best Practice \& Research Clinical Gastroenterology, 27(1), 5-16.

Rajilić-Stojanović, M., Biagi, E., Heilig, H. G. H. J., Kajander, K., Kekkonen, R. A., Tims, S., \& de Vos, W. M. (2011). Global and deep molecular analysis of microbiota signatures in fecal samples from patients with irritable bowel syndrome. Gastroenterology, 141(5), 1792-1801.

Rajilić-Stojanović, M., \& de Vos, W. M. (2014). The first 1000 cultured species of the human gastrointestinal microbiota. FEMS Microbiology Reviews, 38(5), 996-1047.

Rajilić-Stojanović, M., Heilig, H. G. H. J., Molenaar, D., Kajander, K., Surakka, A., Smidt, H., \& de Vos, W. M. (2009). Development and application of the human intestinal tract chip, a phylogenetic microarray: Analysis of universally conserved phylotypes in the abundant microbiota of young and elderly adults. Environmental Microbiology, 11(7), 1736-1751. 
Rajilić-Stojanović, M., Heilig, H. G. H. J., Tims, S., Zoetendal, E. G., \& de Vos, W. M. (2012). Long-term monitoring of the human intestinal microbiota composition. Environmental Microbiology, 15(4), 1146-1159.

Rajilić-Stojanović, M., Smidt, H., \& de Vos, W. M. (2007). Diversity of the human gastrointestinal tract microbiota revisited. Environmental Microbiology, 9, 2125-2136.

Reigstad, C. S., Salmonson, C. E., Rainey, J. F., Szurszewski, J. H., Linden, D. R., Sonnenburg, J. L., ... Kashyap, P. C. (2015). Gut microbes promote colonic serotonin production through an effect of short-chain fatty acids on enterochromaffin cells. The FASEB Journal, 29(4), 1395-1403.

Ridaura, V. K., Faith, J. J., Rey, F. E., Cheng, J., Duncan, A. E., Kau, A. L., ... Gordon, J. I. (2013). Gut microbiota from twins discordant for obesity modulate metabolism in mice. Science, 341(6150), 1241214.

Sevelsted, A., Stokholm, J., Bønnelykke, K., \& Bisgaard, H. (2015). Cesarean section and chronic immune disorders. Pediatrics, 135(1), e92-e98.

Shulman, S. T., Friedmann, H. C., \& Sims, R. H. (2007). Theodor Escherich: The first pediatric infectious diseases physician? Clinical Infectious Diseases, 45(8), 1025-1029.

Strati, F., Cavalieri, D., Albanese, D., De Felice, C., Donati, C., Hayek, J., ... De Filippo, C. (2017). New evidences on the altered gut microbiota in autism spectrum disorders. Microbiome, 5(1), 24.

Swidsinski, A., Loening-Baucke, V., Schulz, S., Manowsky, J., Verstraelen, H., \& Swidsinski, S. (2016). Functional anatomy of the colonic bioreactor: Impact of antibiotics and Saccharomyces boulardii on bacterial composition in human fecal cylinders. Systematic and Applied Microbiology, 39(1), 67-75.

The Human Microbiome Project, C. (2012). Structure, function and diversity of the healthy human microbiome. Nature, 486, 207.

Tims, S., Derom, C., Jonkers, D. M., Vlietinck, R., Saris, W. H., Kleerebezem, M., ... Zoetendal, E. G. (2013). Microbiota conservation and BMI signatures in adult monozygotic twins. The ISME Journal, 7(4), 707-717.

Tun, H. M., Konya, T., Takaro, T. K., Brook, J. R., Chari, R., Field, C. J., ... Kozyrskyj, A. L. (2017). Exposure to household furry pets influences the gut microbiota of infants at 3-4 months following various birth scenarios. Microbiome, 5(1), 40.

Turnbaugh, P. J., Ley, R. E., Mahowald, M. A., Magrini, V., Mardis, E. R., \& Gordon, J. I. (2006). An obesity-associated gut microbiome with increased capacity for energy harvest. Nature, 444, 1027.

Wacklin, P., Tuimala, J., Nikkilä, J., Sebastian, T., Mäkivuokko, H., Alakulppi, N., ... Mättö, J. (2014). Faecal microbiota composition in adults is associated with the FUT2 gene determining the secretor status. PLOS ONE, 9(4), e94863.

Wallace, C. J. K., \& Milev, R. (2017). The effects of probiotics on depressive symptoms in humans: A systematic review. Annals of General Psychiatry, 16, 14. 
Wikoff, W. R., Anfora, A. T., Liu, J., Schultz, P. G., Lesley, S. A., Peters, E. C., \& Siuzdak, G. (2009). Metabolomics analysis reveals large effects of gut microflora on mammalian blood metabolites. Proceedings of the National Academy of Sciences of the United States of America, 106(10), 3698-3703.

Williams, B. L., Hornig, M., Parekh, T., \& Lipkin, W. I. (2012). Application of novel PCRbased methods for detection, quantitation, and phylogenetic characterization of Sutterella species in intestinal biopsy samples from children with autism and gastrointestinal disturbances. mBio, 3(1), e00261-e00211.

Woese, C. R., Kandler, O., \& Wheelis, M. L. (1990). Towards a natural system of organisms: Proposal for the domains Archaea, Bacteria, and Eucarya. Proceedings of the National Academy of Sciences of the United States of America, 87(12), 4576-4579.

Wu, G. D., Chen, J., Hoffmann, C., Bittinger, K., Chen, Y.-Y., Keilbaugh, S. A., ... Lewis, J. D. (2011). Linking long-term dietary patterns with gut microbial enterotypes. Science, 334(6052), 105-108.

Wu, H., Esteve, E., Tremaroli, V., Khan, M. T., Caesar, R., Mannerås-Holm, L., ... Bäckhed, F. (2017). Metformin alters the gut microbiome of individuals with treatment-naive type 2 diabetes, contributing to the therapeutic effects of the drug. Nature Medicine, 23, 850.

Yano, J. M., Yu, K., Donaldson, G. P., Shastri, G. G., Ann, P., Ma, L., ... Hsiao, E. Y. (2015). Indigenous bacteria from the gut microbiota regulate host serotonin biosynthesis. Cell, 161(2), 264-276.

Yatsunenko, T., Rey, F. E., Manary, M. J., Trehan, I., Dominguez-Bello, M. G., Contreras, M., ... Gordon, J. I. (2012). Human gut microbiome viewed across age and geography. Nature, 486, 222.

Zoetendal, E. G., Akkermans, A. D., Akkermans-van Vliet, W. M., de Visser, A. J. G. M., \& de Vos, W. M. (2001). The host genotype affects the bacterial community in the human gastrointestinal tract. Microbial Ecology in Health and Disease, 13, 129-134.

Zoetendal, E. G., Akkermans, A. D., \& de Vos, W. M. (1998). Temperature gradient gel electrophoresis analysis of 16S rRNA from human fecal samples reveals stable and hostspecific communities of active bacteria. Applied and Environmental Microbiology, 64(10), 3854-3859. 


\title{
Microbioma intestinal y su papel para la salud humana
}

\begin{abstract}
Resumen
Los humanos viven en la relación cercana con el ecosistema microbiano complejo que se denomina microbioma. La microbioma está concentrada en la última parte del tracto gastrointestinal, donde fermenta los residuos de la comida no digerida y produce varios metabolitos que tienen influencia sistemática en la fisiología humana. La composición de la microbioma está influenciada por los factores genéticos y ambientales que forman un ecosistema único en cada humano. A pesar de las variaciones composicionales considerables, el output funcional del ecosistema es muy similar en todos los individuales sanos. Aunque todavía no es posible definir la microbioma normal, las comparaciones entre los pacientes que sufren algunas enfermedades crónicas con etiología desconocida y los controles han demostrado que los pacientes tienen una composición específica, disbiótica de microbioma. Mientras todavía queda por determinar si la disbiosis de la microbioma es un factor etiológico o consecuencia de la enfermedad, estos hallazgos han estimulado investigaciones intensivas de la microbioma. Numerosas funciones atestadas de microbioma incluyen la contribución a la digestión, síntesis de metabolitos esenciales (vitaminas y aminoácidos) y diafonía intensiva con los sistemas inmune, endocrino y nervioso. Aunque este campo de investigación todavía está en una fase temprana, está claro que los metabolitos microbianos tienen varios efectos en los humanos, incluyendo efecto beneficial directo, toxicidad, pero también interacciones más finas, dado que los productos microbianos pueden funcionar como moléculas de regulación inmune y de neuro-señalización. La red compleja de interacciones bidireccionales entre la microbioma y los humanos está por explorar con potencial muy alto para desarrollar estrategias novedosas para preservar y mejorar la salud.
\end{abstract}

Palabras clave: microbioma, composición, disbiosis, salud humana

Received: January 4, 2018 